\title{
A Integração Local dos Congoleses Refugiados e Solicitantes de Refúgio no Rio de Janeiro
}

\author{
The Local Integration of Congolese Refugees and Asylum Seekers in Rio de Janeiro
}

La Integración Local de los Congoleses Refugiados y Solicitantes de Refrigo en el Río de Janeiro

Maya Fernandes Ishizuka

Bacharel em Administração pela Universidade Federal do Rio de Janeiro http://lattes cnpq.br/0028935309195927 https://orcid.org/0000-0002-5394-8642 ishfmaya@gmail.com

Vanessa Brulon Doutorado em Administração pela Escola Brasileira de Administração Pública e de Empresas da Fundação Getúlio Vargas (EBAPE/FGV) Professor Adjunto do Departamento de Administração da FACC/UFRJ http://lattes.cnpq.br/7455566261719778 https://orcid.org/0000-0002-0118-4089 vanessabrulon@facc.ufr.br

Resumo: A presente pesquisa tem por objetivo compreender em que medida o Plano Estadual de Políticas de Atenção aos Refugiados, implementado no Rio de Janeiro desde 2014, auxilia na integração local dos refugiados e solicitantes de refúgio provenientes da República Democrática do Congo que residem no estado do Rio de Janeiro. Para este estudo, de caráter qualitativo, a integração local foi tratada por meio de diferentes categorias pelas quais se constitui. A partir destas, foram analisadas as percepções dos próprios refugiados, solicitantes de refúgio e funcionários de diferentes áreas da Cáritas/RJ por meio de entrevistas semi-estruturadas e observação de campo. Ao fim das análises, foi possível perceber de que modo ocorre o processo, observar lacunas no Plano Estadual, bem como o papel fundamental exercido pelos Centros de Acolhida na obtenção dos direitos previstos em lei.

Palavras-chave: Refugiados, Políticas Públicas, Cáritas, República Democrática do Congo.

\begin{abstract}
The following research aims to understand to what extent the Plano Estadual de Políticas de Atenção aos Refugiados (State Plan for Polices Addressed to Refugees), implemented in Rio de Janeiro since 2014, helps on the local integration of refugees and asylum seekers from the Democratic Republic of Congo residing in the State of Rio de Janeiro. For this qualitative research, the local integration was addressed under different categories, from which it was discussed the perception of refugees, asylum seekers and employees from Cáritas-RJ. The statements were obtained through data collection using semi structured interviews and field observation. By the end of the analysis, it is possible to understand how the processes occurs, what are the gaps, critical points regarding housing and employment, and key role of hospitality centers in order to help obtain the rights foreseen by the law.

Palavras-chave: Refugees, Public Policy, Cáritas, Democratic Republic of Congo
\end{abstract}

Resumen: La presente investigación tiene por objetivo comprender en qué medida el Plan Estadual de Políticas de Atención a los Refugiados, implementado en Río de Janeiro desde 2014, auxilia en la integración local de los refugiados y solicitantes de refugio provenientes de la República Democrática del Congo que residen en el estado de Rio de Janeiro. Para este estudio, de carácter cualitativo, la integración local fue tratada por medio de diferentes categorías por las cuales se constituye. A parti de estas, se analizaron las percepciones de los propios refugiados, solicitantes de refugio $y$ funcionarios de diferentes áreas de Cáritas / RJ por medio de entrevistas semiestructuradas y observación de campo. Al final de los análisis, fue posible percibir de qué modo ocurre el proceso, observar lagunas en el Plan Estadual, así como el papel fundamental ejercido por los Centros de Acogida en la obtención de los derechos previstos en ley.

Palabras clave: Refugiados, Políticas Públicas, Cáritas, República Democrática del Congo.

Texto completo em português: http://www.apgs.ufv.b Full text in Portuguese: http://www.apgs.ufv.br

\section{INTRODUÇÃO}

Em 2015, o número de pessoas refugiadas em todo o mundo chegou a 20,2 milhões - um aumento alarmante de $78 \%$ em comparação com o ano anterior - , sendo o maior resultado registrado em duas décadas (ONU, 2015). A maior parte da apuração conta com as pessoas que são obrigadas a deixar seu país de origem devido a guerras, conflitos e perseguições.

Segundo dados do Alto Comissiariado das Nações Unidas para Refugiados - ACNUR -, os países e regiões em desenvolvimento acolhem $86 \%$ dos refugiados no mundo, sendo o Brasil o principal país acolhedor dessa população na América Latina. De acordo com o relatório elaborado pelo Comitê Nacional para os Refugiados CONARE -, as solicitações de refúgio no país aumentaram mais de $2.868 \%$ entre 2010 e 2015 - saltando de 966 solicitações em 2010 para 28.670 em 2015. Atualmente o Brasil tem cerca de 8.863 refugiados reconhecidos pelo governo (ACNUR, abril de 2016).
O Brasil é signatário dos principais tratados internacionais de direitos humanos e faz parte da Convenção das Nações Unidas de 1951 sobre o Estatuto dos Refugiados e do Protocolo de 1967. Além disso, promulgou em 1997 dentro da Constituição Federal a Lei no 9.474, de 22 de Julho de 1997, estabelecendo, através desta, mecanismos para a implementação do Estatuto do Refugiado e garantindo, assim, os direitos fundamentais dos indivíduos que necessitam de proteção (Cáritas, 2016).

O Rio de Janeiro, em particular, foi o primeiro estado a desenvolver um Plano Estadual de Políticas de Atenção ao Refugiado, que visa traçar às ações concretas para a garantia dos direitos já estabelecidos por lei. Esse avanço deve-se, em parte, à alta concentração de refugiados no estado, uma das maiores do país: estima-se hoje que o Rio de Janeiro abrigue cerca de quatro mil refugiados e quase 2500 solicitantes de refúgio (Cáritas, 2016).

Dentre a crescente entrada de solicitantes de refúgio no estado do Rio de Janeiro - em especial na capital - destaca-se a 
predominância de estrangeiros vindos da República Democrática do Congo - RDC -, que atualmente representam 56\% dos refugiados e $20 \%$ dos solicitantes de refúgio na região (Cáritas, 2016). Os congoleses chegam ao Brasil fugindo de uma guerra civil instaurada em seu país (Valenzola, 2013), além dos altos índices de estupro, que refletem no crescimento do número de mulheres refugiadas; neste ano, o número de mulheres solicitantes de refúgio ultrapassou o número de homens no Rio de Janeiro (Cáritas, 2016).

Ainda que o Brasil, em especial o estado do Rio de Janeiro, esteja avançando com relação às leis para a população refugiada, diversos são os problemas estruturais relatados em termos de sua integração na sociedade. Apesar das garantias legais referentes aos direitos à saúde, educação, moradia, emprego e renda que são previstas, são poucas as políticas que auxiliam esses refugiados a conseguir acesso aos seus direitos. Grande parte do auxílio prestado aos solicitantes de refúgio e refugiados é proveniente de associações não governamentais, sendo o centro de acolhida Cáritas Arquidiocesana a principal referência em termos de assistência a essa população no Rio de Janeiro (ONU, 2014).

Assim, tem-se por objetivo neste trabalho compreender em que medida o Plano Estadual de Políticas de Atenção aos Refugiados, implementado no Rio de Janeiro desde 2014, auxilia na integração local dos refugiados e solicitantes de refúgio provenientes da República Democrática do Congo que residem no estado do Rio de Janeiro.

Para tal, inicia-se com a discussão acerca do refúgio no Brasil e no Rio de Janeiro, a apresentação da noção de integração local, bem como uma revisão das leis federais e planos deste estado voltados para refugiados. Em seguida, explicita-se os métodos utilizados para o desenvolvimento da pesquisa, a análise de dados, com base nas categorias propostas para analisar a integração local dos refugiados e, por fim, uma breve conclusão.

\section{FUNDAMENTAÇÃO TEÓRICA}

\subsection{O Refúgio no Brasil e no Rio De Janeiro}

No âmbito das migrações, existe um grupo específico que deixa seus países em busca de proteção, devido aos conflitos e guerras que acarretam na violação dos direitos humanos por diversas razões (Moreira, 2010). Segundo dados publicados em 2016 pelo ACNUR, estimam-se que atualmente cerca de 59,5 milhões de pessoas são vítimas do deslocamento forçado, ocasionado pelas situações previamente citadas. Ainda de acordo com o relatório, o número total de refugiados cresceu significativamente nos últimos quatro anos. Em geral, os principais contribuintes para essa estatística são a guerra na Síria e os Conflitos Armados que ocorrem na África Subsaariana, Oriente Médio, Ásia e Pacífico.

Atualmente o Brasil é o país que mais recebe refugiados na América Latina, conforme dados do ACNUR (2015). Em meio ao aumento exacerbado das migrações forçadas, somadas às medidas de protecionismo instauradas nos Estados Unidos da América - EUA - e Europa (FRANCO, 2016), essas pessoas veemse forçadas a procurar asilo em outros continentes, sendo o território brasileiro um desses novos destinos.
O estado do Rio de Janeiro, em especial, é um dos principais pontos de entrada e abrigo dos entrantes em busca de refúgio no país. Segundo relatório publicado pela Cáritas/RJ, até dezembro de 2015, o estado possuía 4.111 refugiados reconhecidos por lei quase metade dos 8.863 que residem no país - além de 2.410 solicitantes de refúgio - cerca de $10 \%$ do total nacional - (Cáritas, 2016; ACNUR, 2016). O fluxo de solicitantes no Rio de Janeiro no ano de 2015 também teve um crescimento repentino: segundo dados da Cáritas (2016), o aumento foi de $82 \%$ em relação ao ano anterior; foram registradas 458 pessoas que chegaram ao estado em 2014, versus 834 pessoas no ano seguinte.

Ainda de acordo com informações fornecidas pelo Centro de Acolhida (Cáritas, 2016), a partir do século 21, os refugiados provenientes da República Democrática do Congo representaram um aumento consistente, tornando-se a nacionalidade que supera as demais, com base às novas chegadas ao estado do Rio de Janeiro e a $4^{\mathrm{a}}$ nacionalidade em número de refugiados reconhecidos no país (ACNUR, 2016). Segundo relatório da Cáritas (2016), até 2014 os congoleses representavam 36\% do total de solicitações de refúgio no estado; em 2015, esse número subiu para quase $40 \%$. Apenas no primeiro trismestre de 2016 , os congoleses somam mais de $50 \%$ das chegadas no Rio de Janeiro.

Outro dado interessante é que dentre a população solicitante presente no país, cerca de $80 \%$ são do sexo masculino. Entretanto, no Rio de Janeiro, os homens representaram somente $50 \%$ dos entrantes em 2016 (Cáritas, 2016). Tal fato pode ser justificado devido ao aumento de mulheres em busca de proteção, em especial vindas da República Democrática do Congo, devido ao uso da violência sexual como tática de guerra, visando desestabilizar às famílias e dominar populações através do ataque direto à mulher (Valenzola, 2013).

Assim, visto que o número de solicitações de refúgio no Brasil e no mundo cresce de maneira mais veloz a cada ano, enxerga-se a necessidade de fortalecimento da lei em vigor, bem como, a criação de políticas públicas mais específicas, principalmente relacionadas à integração local dos refugiados. Como afirma Moreira (2012, p.306), "Precisamos superar os obstáculos internos, em torno da efetividade dessa política, sobretudo em termos da integração local".

\subsection{A Integração Local: Desafios e Avanços}

A integração local consiste no processo que se desenvolve quando o refugiado passa a inserir-se em novo contexto, no país de destino, em meio à comunidade receptora (Moreira, 2012). Tal processo envolve inserir o cidadão de forma eficiente em diversos eixos da sociedade, como educação, emprego, moradia e ambiente sócio-cultural (CEIPAR, 2014). Em uma definição mais completa, descrita por Moreira (2014, p.90):

A integração deve ser entendida como um termo abrangente, abarcando um conjunto de processos em múltiplas esferas, cada qual possuindo seu próprio modo de operação e significado, desenrolando-se em temporalidades e trajetórias que lhes são peculiares e produzindo resultados variáveis (MOREIRA, 2014,p. 20). 
Assim, entendemos a integração local como uma compreensão unificada de diversas atividades e ações, que abrangem diferentes áreas do ambiente social e que funcionam de maneiras distintas, mas que fazem parte de uma única necessidade: a inclusão da população entrante no país em meio à população local, seu acesso aos bens e serviços aos quais tem direito e a adaptação às normas e processos locais.

Consoante com Moreira (2012, p. 249), devido à ausência de campos de refugiados no Brasil, diferentemente de alguns outros países, "a liberdade de movimento dos refugiados é garantida no país, assim como o direito ao trabalho, ainda na condição de solicitante de refúgio". Tal fato por si só já é um facilitador da integração local, porém, não é o suficiente para garanti-la. Conforme Franco (2016), o desemprego é ainda presente na vida dos refugiados, não obstante os avanços jurídicos obtidos.

No Brasil, a rede de proteção aos refugiados compõem-se por meio de diferentes órgãos: o Alto Comissário das Nações Unidas para Refugiados (ACNUR), que atua em cooperação com o Comitê Nacional para os Refugiados (CONARE) e, também, mediante às parcerias e projetos com organizações não governamentais. (ONU, 2014). Estas, também conhecidas como Centros Acolhida, têm funções diretamente ligadas à assistência humanitária e a integração dos refugiados. Como explica Jubilut (2014,p.8), os Centros de Acolhida possuem as funções de:

permitir o acesso pelo solicitante de refúgio a programas de assistência e integração social e 2) verificar se o solicitante e considerado refugiado pelo ACNUR, a fim de gozar da proteção internacional. Não tem ele força vinculante para o governo brasileiro que é a quem compete decidir sobre o pedido de refúgio em nosso território (JUBILUT, 2014,p.8).

Um dos principais Centros de Acolhida no Brasil é a Cáritas Arquidiocesana, organização não governamental que presta serviços aos refugiados e solicitantes de refúgio no país em parceria com os órgãos públicos e a Organização das ações Unidas -ONU - (ACNUR, 2013). A Cáritas possui duas unidades de Atendimento, localizadas nas capitais dos estados de São Paulo e Rio de Janeiro.

Mesmo com o auxílio prestado pelos Centros de Acolhida, os refugiados e solicitantes ainda se deparam com dificuldades para encontrar trabalho e acessar aos serviços sociais, principalmente devido à falta de informações não apenas por parte dos entrantes, como, também, dos órgãos públicos que possuem pouco conhecimento relativo às especificidades da condição de refúgio e das leis aplicáveis (CEIPAR, 2014).

Albuquerque et al. (2016) relacionam a dificuldade da integração local como parte de um desequilíbrio na estrutura social, justificada pela burocracia estatal, falta de preparo dos funcionários públicos e a falta de informação da população a respeito do acesso aos bens e serviços básicos previstos em lei, como direitos de todos os cidadãos.

A integração local compõe-se, então, de diferentes aspectos sociais, contemplando o acesso aos serviços básicos aos quais todo o cidadão reconhecido por lei tem direito, de acordo com a Constituição Da República Federativa Do Brasil (1988). Ainda assim, para que o refugiado possa ter acesso a tais direitos, faz-se necessário o estabelecimento de serviços e políticas públicas específicas.

\subsection{As Leis Federais e o Plano Estadual do Rio de Janeiro para Refugiados}

As políticas públicas visam enfrentar aos problemas públicos; estas demonstram a intenção do governo em buscar soluções a uma questão relevante para o coletivo (Secchi, 2013). Apesar do papel central das autoridades, segundo Souza (2006), muitos teóricos reconhecem que elas não atuam isoladamente na formulação destas políticas - diferentes grupos podem interagir com o governo nesta função - (Souza, 2006). O autor explica, ainda, que das políticas públicas podem derivar planos, programas, projetos, bases de dados ou sistema de informação e pesquisas, mostrando que sua criação deve ultrapassar o âmbito teórico e exercer função prática na sociedade, por meio de ações que visem sanar às questões sobre as quais foi elaborada.

Conforme Secchi (2013), as políticas públicas abrangem diversas áreas, dentro das quais existem assuntos específicos que dependem também de políticas específicas. Vemos tal especificidade no caso dos refugiados, que compõe uma população em contexto diferente dos demais cidadãos. Algumas das ações de políticas públicas para os refugiados são descritas a seguir.

De acordo com o ACNUR, no século $X X$, diversos foram os acordos internacionais elaborados em prol da população refugiada. Dentre os principais documentos reconhecidos internacionalmente, temos Estatuto dos Refugiados, elaborado a partir da Convenção de 1951 sediada em Genebra. O ACNUR, criada um ano antes, teve suas responsabilidades definidas através Convenção Relativa Ao Estatuto Dos Refugiados (1951, p.1), sendo estas:

O Alto Comissário das Nações Unidas para os Refugiados tem a incumbência de zelar pela aplicação das convenções internacionais que assegurem a proteção dos refugiados, e reconhecendo que a coordenação efetiva das medidas tomadas para resolver este problema dependerá da cooperação dos Estados com o Alto Comissário (CONVENÇÃO RELATIVA AO ESTATUTO DOS REFUGIADOS (1951,p.1).

Em relação ao Brasil, este busca esforçar-se para fornecer instrumentos e assegurar a proteção aos refugiados, sendo considerado pioneiro na proteção internacional (CEIPAR, 2014). O país é signatário dos principais tratados internacionais referentes ao tema, como a Convenção de 1951 e o Protocolo de 1967. Após a redemocratização no fim dos anos 1980, a questão dos refugiados voltou a ser discutida internamente e em 22 de julho 1997 foi promulgada a legislação específica para Refugiados (Lei nº 9.474/97) que contempla uma série de provisões que garantem os direitos de cidadão do refugiado no Brasil.

Com a implementação da lei, foi criado também o Comitê Nacional para os Refugiados (CONARE), que tem como principal função julgar os pedidos de refúgio, e classificá-los como elegíveis ou não. Além disso, também é o orgão responsável por determinar a perda da condição de refugiado e "orientar e coordenar ações necessárias à eficácia da proteção, assistência e apoio jurídico aos refugiados" (BRASIL. Lei no 9.474 de 22 de julho de 1997).

Observando as ações voltadas para a integração local dos refugiados e solicitantes de refúgio, percebe-se que nos últimos cinco anos novos processos visando à garantia desse direito estão sendo executados pelo Governo e pelo ACNUR. Em seu último relatório, publicado em 2016, o CONARE apresentou medidas 
recentes visando ao fortalecimento do sistema nacional de refúgio. Dentre as medidas, algumas visam soluções duráveis para a integração local, como por exemplo, a parceria com o Ministério do Trabalho e Previdência Social (MTPS); a desburocratização do acesso ao Programa Federal "Minha Casa, Minha Vida"; a pactuação com diversos estados e municípios, tais como: Porto Alegre, Rio de Janeiro, Curitiba e Belo Horizonte, para a criação de Centros de Referência e Acolhida a Migrantes e Refugiados (Rede CRAl) já em funcionamento hoje na cidade de São Paulo.

A nível estadual, o Rio de Janeiro foi o primeiro no país a criar um Plano Estadual de Atenção aos Refugiados, publicado em 2014, em consonância com a busca e promoção dos direitos humanos (CEIPAR, 2014). Seu principal, segundo o próprio documento, é "explicitar as garantias já expressamente previstas pela legislação pátria e pelos documentos internacionais dos quais o Brasil seja parte". Tal propósito dá-se por meio da abordagem da integração local através de eixos temáticos (assim, denominados pelo Plano: documentação, educação, emprego e renda, saúde, moradia e ambiente sociocultural).

O Plano Estadual foi concebido pelo Comitê Estadual Intersetorial de Políticas de Atenção aos Refugiados - CEIPAR -, instituído por meio do decreto no 42.182 de 2009, que é coordenado pela Secretaria de Assistência Social e Direitos Humanos do Rio de Janeiro. De acordo com Frey (1999), a formação de grupos especiais integrando foros de competência de decisão no âmbito das políticas públicas, ao instituir projetos ou programas, é possível. O CEIPAR é um exemplo prático: sua composição abrange não apenas membros da ordem pública, como também, instituições não governamentais, como a Ordem dos Advogados do Brasil e a Cáritas Arquidiocesana do Rio de Janeiro.

A elaboração, implementação e acompanhamento do Plano Estadual é o principal objetivo do comitê. O documento contém informações gerais a respeito da integração local, dividida por categorias, seguida por recomendações gerais. Para cada um dos eixos sob os quais o plano divide-se, foram traçadas diretrizes, objetivos e ações para assegurar os direitos previstos em lei, especificando responsáveis e prazos para cada um destes. A partir de cada diretriz e ação, o plano prevê o desenvolvimento de elementos tangíveis que tem como objetivo auxiliar e informar a população refugiada durante o processo de integração local. Estes elementos são chamados pelo documento de produtos e consistem em materiais, eventos, convênios e publicações elaborados em parcerias entre o governo federal, estadual, o ACNUR e Cáritas.

Tendo como base o Plano Estadual de Políticas de Atenção aos Refugiados, o presente estudo visa identificar à eficácia e possível melhoria do auxílio prestado aos refugiados e solicitantes de refúgio congoleses residentes do estado do Rio de Janeiro, com relação à integração local.

\section{PROCEDIMENTOS METODOLÓGICOS}

A presente pesquisa, de caráter qualitativo, busca compreender em que medida o Plano Estadual de Atenção aos Refugiados, implementado no Rio de Janeiro desde 2014, auxilia na integração local dos Refugiados e Solicitantes de Refúgio provenientes da República Democrática do Congo que residem no Estado do Rio de Janeiro.

Para tal, a coleta de dados foi realizada por meio do documento publicado pela CEIPAR, o "Plano Estadual de Políticas de Atenção aos Refugiados", complementado por entrevistas individuais semiestruturadas com refugiados, solicitantes e funcionários do Centro de Acolhida e observação realizada na sede da Cáritas no Rio de Janeiro. Foram realizadas entrevistas com oito refugiados e solicitantes de refúgio provenientes da República Democrática do Congo, e quatro com funcionários da Cáritas/RJ, totalizando doze entrevistas. A escolha dos participantes foi feita a partir da aceitação voluntária dos refugiados e funcionários na concessão das entrevistas, após assinatura de um termo de confidencialidade que restringe a publicação de dados que possam identificar os entrevistados.

Realizamos, também, a observação na sede de atendimento da Cáritas/RJ, localizado na Tijuca, mesmo local onde ocorreram as entrevistas. Durante o expediente de funcionamento, nos dias de maior fluxo de refugiados, terças e quintas-feiras, foram observados o processo de atendimento e o comportamento padrão dos refugiados. Não foi possível participar dos atendimentos individuais ou acompanhar os processos profundamente, dada a confidencialidade das informações e a alta demanda de atendimentos realizados. Após cada dia de análise, foi elaborado um relatório de campo, com os principais pontos investigados. Visando evitar o constrangimento dos examinados, bem como não inibir comportamentos, as notas de campo foram escritas apenas após o fim da observação.

O conteúdo das entrevistas e das notas de campo, somado ao documento, foram classificadas através das categorias de análise. A partir deste material, aplicamos a técnica de análise de conteúdo; de acordo com Vergara (2014), esta, tem como característica, analisar as comunicações, de modo a associa-la ao conteúdo e aos significados da mensagem. As categorias utilizadas para análise, desenvolvidas a partir do referencial teórico, encontram-se na figura a seguir: 
Figura 1. Categorias de Análise

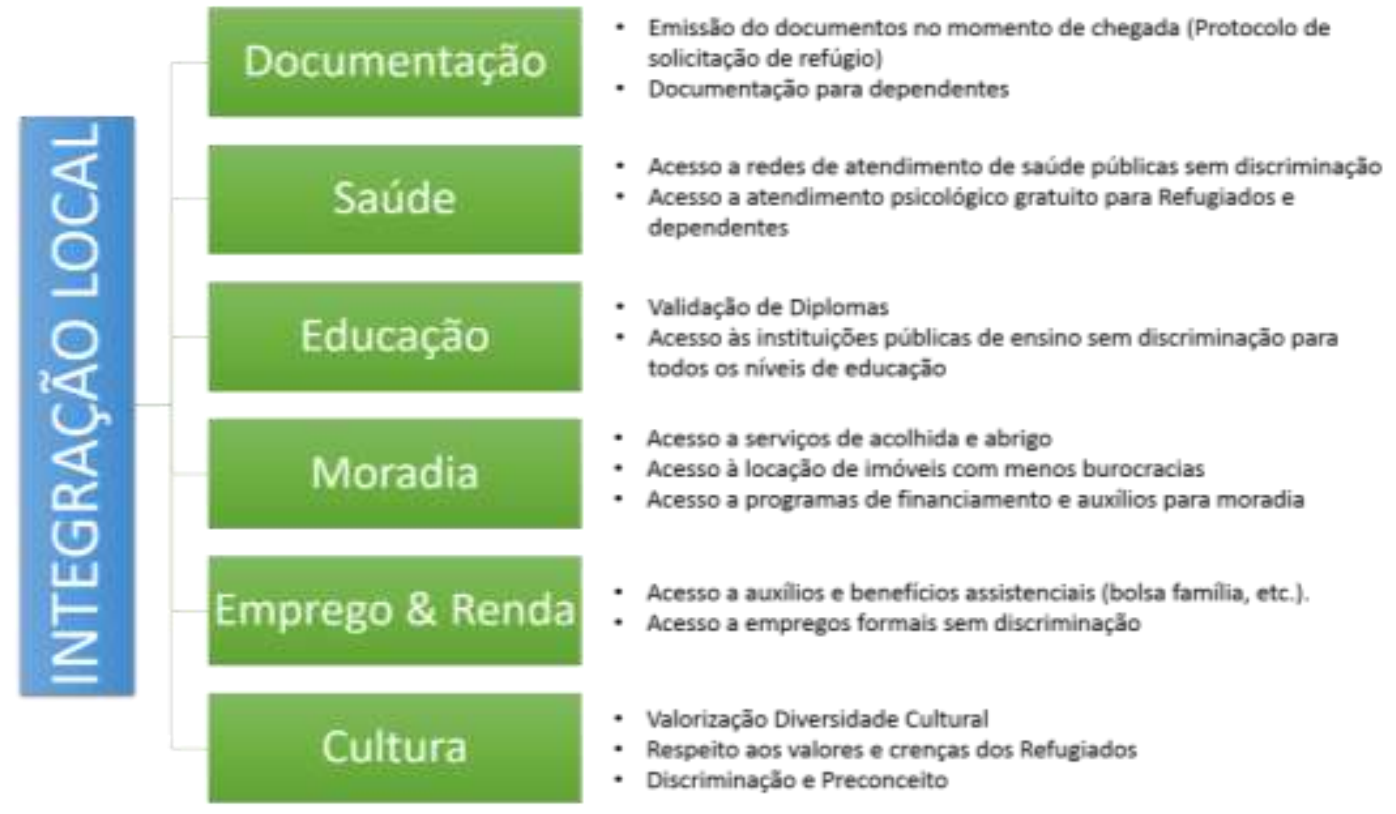

Fonte: Elaboração própria dos autores

\section{ANÁLISE DE DADOS}

\subsection{Documentação}

A Documentação é o passo inicial para a obtenção dos direitos de cidadão ao chegar ao Brasil; sem os documentos, o solicitante de refúgio não terá acesso a nenhum serviço público ou auxílio do governo. De acordo com a Lei № 9.474/97, em seu artigo 6ํㅡ, está previsto ao refugiado o direito à obtenção da cédula de identidade comprobatória de sua condição jurídica, carteira de trabalho e documento de viagem. O Plano Estadual de Políticas de Atenção aos Refugiados (2014, p.5) cita também os documentos aos quais o entrante tem direito ao realizar a solicitação de refúgio: "Ao pleitear auxílio humanitário, o(a) refugiado(a) recebe inicialmente a proteção expressa de maneira formal em um documento".

De acordo com a Coordenadora da Assistência Social da Cáritas, a obtenção dos documentos iniciais ocorre a partir do seguinte processo:

O solicitante de refúgio quando ele chega, ele tem direito a ter três documentos, que é o Protocolo, o CPF e a Carteira de Trabalho. Pra ele conseguir o protocolo, ele precisa formalizar na Policia Federal a solicitação de refúgio; então normalmente ele vem até a Cáritas [...],e ai a gente orienta eles dentro do termo de solicitação de refúgio, e encaminha eles para a Policia Federal - lá ele é identificado e recebe esse protocolo. Com o protocolo ele retorna pra a Cáritas e a gente faz a entrevista social pra traçar um plano de integração junto com ele e nesse momento a gente já orienta sobre como fazer o CPF e a carteira de trabalho (Funcionário 1).

O procedimento foi explicado por todos os funcionários de maneira similar. De acordo com as entrevistas, espera-se que o solicitante tenha os dois documentos em menos de um mês. Dois dos entrevistados relataram um problema sistêmico no agendamento da carteira de trabalho, que ocasionou atrasos, fato que pode ter ocorrido devido ao alto fluxo de solicitações no estado em 2015: um aumento de $82 \%$ nos pedidos de refúgio em relação ao Ano Anterior, segundo relatório da Cáritas (2016).

Conforme os solicitantes de refúgio entrevistados, o processo para a obtenção dos documentos ocorreu normalmente. Não houve reclamações com relação ao tempo de espera. Entretanto, a Migrante 1 afirma ouvir relatos de dificuldades na hora de conseguir a documentação:

Hoje quando as pessoas chegam demora pra poder conseguir o protocolo [...] Hoje, pra poder conseguir a carteira de trabalho, por exemplo, quando você vai antes de poder fazer, você tem que ir fazer o CPF, depois tem que aguardar mais ou menos 2 semanas, pra poder o CPF entrar no sistema, o sistema aceitar e você pode fazer o agendamento, pode ir no ministério do trabalho pra conseguir a carteira de trabalho (Migrante 1).

Apesar da aparente facilidade do processo, uma situação alarmante é a condição de vida do entrante durante à espera pelo documento. Durante a entrevista, a coordenadora da assistência social levantou o seguinte questionamento:

[...]porque como eu falei no início, eles demoram de 15 a 20 dias
para ter documentação... e o que eles fazem durantes esse período?
Onde é que eles dormem? O que eles comem? A gente fala disso o
tempo todo pro poder público, porque o fato de ter uma lei que
garanta o documento ele é muito importante. [...] mas não é
suficiente pra garantir a efetivação do direito (Funcionário 1).

Assim, é importante relembrar que tanto a Lei o 9.474/97, quanto o Plano Estadual, ainda que admitam que sem o documento a pessoa não tem acesso aos direitos básicos, não contemplam nenhum tipo de ação ou plano referente ao período em que o entrante aguarda a emissão dos documentos. Atualmente, segundo os entrevistados, no caso dos congoleses, quando chegam ao Brasil, tendem a buscar auxílio junto à comunidade local, com outras pessoas de sua nacionalidade que já estiveram na mesma situação e atualmente encontram-se mais estáveis para auxiliar os recém-chegados.

Além do processo para a obtenção, outro ponto relevante é o conhecimento da população acerca da documentação. Em tese, o protocolo seria um documento de identificação, semelhante a um Registro Nacional de Estrangeiros (RNE), porém, de caráter provisório. Entretanto, de acordo com as afirmações de funcionários e refugiados, muitas pessoas não dão credibilidade ao protocolo, desconfiando que ele seja um documento válido, dado que seu 
formato é diferente de uma identificação tradicional. Um dos funcionários da Cáritas confirma a distinção do documento no trecho a seguir:

[...]O protocolo parece uma folha A4 cortada ao meio, e ai ele não pode ser plastificado como a nossa identidade, então é esse formato, com uma foto e os dados, nome filiação, pais, data de nascimento, mas não parece um documento... ainda que tenha carimbo da Polícia Federal, as pessoas não conhecem, então... (Funcionário 2)

Atualmente, segundo os funcionários da Cáritas, algumas mudanças, visando minimizar essa barreira, já foram realizadas, tais como: a unificação do modelo de protocolo para todo o Brasil; a publicação de boletins e circulares informando os hospitais, unidades de saúde e delegacias sobre o protocolo ,reconhecendoo como um documento válido.

Além disso, o Plano Estadual contempla em seus produtos: "Sensibilizar órgãos de segurança acerca dos direitos dos(as) solicitantes de refúgio e dos(as) refugiados(as)" e "Promover alteração do protocolo de solicitação de refúgio - de maneira a torná-lo mais completo". Assim, busca-se sanar por meio destas a falta de conhecimento acerca do tema, bem como tornar o documento mais passível de gerar confiança. Segundo os funcionários, essas ações já estão sendo implementadas pela própria Cáritas, por meio de campanhas de sensibilização junto aos órgãos públicos - mediante aos informativos em delegacias e hospitais, por exemplo.

Apesar da distinção, com os documentos em mãos, os solicitantes já conseguem ter acesso aos direitos básicos, como matricular seus filhos na escola, marcar consultas e receber atendimento mediante ao Serviço Único de Saúde (SUS), além de inserir-se formalmente no mercado de trabalho.

Após ter o pedido de refúgio deferido pelo CONARE - processo que hoje leva cerca de dois anos -, segundo os entrevistados refugiados ), eles podem emitir o RNE e não precisa mais fazer uso do protocolo.

\subsection{Saúde}

A saúde é um direito básico contemplado na Constituição Federal de 1988. O Brasil possui atendimento público gratuito nessa área, por meio do Sistema Único de Saúde (SUS), garantido por lei o acesso integral, universal e gratuito desde 0 atendimento ambulatorial até cirurgias e transplantes.

Como descrito anteriormente, segundo relatório da Cáritas (2016), a população refugiada proveniente do Congo possui um número de mulheres, gestantes e criança superior à média geral da população refugiada no Brasil. Dado esse fato, a necessidade por atendimento médico tende a aumentar, visto que gestantes e crianças necessitam de maior acompanhamento.

O direito à saúde para a população refugiada contempla não só o atendimento através do sistema de saúde público, como também o acesso aos serviços subjacentes à saúde, tais como água potável e saneamento básico (CEIPAR, 2014). O Plano Estadual leva também em consideração os problemas físicos e emocionais que podem ser acarretados pela condição de refúgio. De acordo com o documento (2014, p. 12):
As populações refugiadas tendem a ser mais vulneráveis a transtornos psicológicos e doenças mentais. A presença de uma rede de apoio integrada é fundamental para a integração desses indivíduos. Ainda, a população refugiada, por preconceito, desinformação e dificuldade de acesso, encontra problemas para obter atendimento básico na rede pública de saúde.

Tal distinção - referente aos problemas físicos e mentais- é justificada ao considerarmos o que acarreta na condição de refúgio; a maioria dos refugiados deixa seus países devido às situações traumáticas que podem ocasionar transtornos psicológicos.

Logo, o plano reforça a necessidade de acessibilidade e aceitação dos refugiados durante 0 atendimento médico, que muitas vezes enfrentam a barreira do idioma ao relatar sintomas, além de eventuais casos de preconceito, conforme explicitados em alguns dos depoimentos dos funcionários da Cáritas e dos próprios Congoleses:

Muitos hospitais não reconhecem o protocolo como um documento válido, então as vezes eles têm problema de encaminhamento, fora a discriminação: "você é estrangeiro, você não pode ser atendido", "você não fala português eu não to entendo o que você ta falando" [...] "você não sabe me falar qual parte do teu corpo está doendo, então tchau, não é minha obrigação ficar aqui te atendendo" (Funcionário 4).

A barreira da desinformação no Rio de Janeiro está sendo solucionada com ações de sensibilização feitas pelos próprios funcionários:

A gente tenta empodeira-las do conhecimento de que com o protocolo eles têm acesso à saúde [...]. Eles falam o endereço onde eles estão residindo e a gente procura na internet a UPA mais próxima, a clínica da família ... muitas vezes até faz contato telefônico com o local pra dar um preâmbulo do que é o refugiado (Funcionário 2).

No curso de língua portuguesa, coordenado pela Cáritas, conceitos básicos para o uso diário do idioma falado são ensinados, inclusive a respeito da saúde, visando facilitar ao processo de atendimento:

[...] então a gente faz todas as aulas direcionadas para o que eles mais precisam que é saúde, educação [...]a saúde assim de modo geral, não necessariamente só ir ao médico, mas relatar uma dor [...] (Funcionário 3).

Os funcionários entrevistados também destacam as parcerias na área da saúde com as Secretarias estaduais e municipais da região. Mediante à parceria, a Cáritas desenvolveu uma cartilha com informações básicas, além da realização periódica de feiras de saúde.

Apesar das dificuldades apresentadas, a maioria dos refugiados e solicitantes não se queixaram do atendimento. Em geral, todos os que buscaram atendimento médico conseguiram, ainda que houvesse um tempo de espera considerável. Em conformidade com relatos de uma refugiada, em conversa informal durante a observação, na República Democrática do Congo, benefícios como saúde e educação não estão disponíveis na rede pública, sendo necessário pagar para obter acesso ao serviços.

Além do direito ao atendimento básico, os refugiados também contam com atendimento psicológico, fornecido pelo Cáritas; entretanto, os funcionários percebem que a demanda por os suportes individuais não ocorre como o esperado, conforme afirmam os funcionários da Cáritas:

[...] muitos não entendem o funcionamento de um psicólogo, o que você deve fazer, confunde as vezes com uma assistente social, e 
quando percebe que é pra você começar a falar e se expor e tentar resolver os problemas interiores, tem uma certa limitação, eles começam a desestimular [...] (Funcionário 3).

A baixa procura por atendimento psicológico individual pode ser explicada novamente pela barreira do idioma e possivelmente por um desconhecimento acerca do processo de atendimento psicológico, como citado no trecho anterior.

Dentre os produtos previstos no Plano Estadual que já estão sendo executados, podemos citar, além da sensibilização e da garantia do atendimento, a parceria com os hospitais; a informação a respeito da rede de atendimento e a presença do serviço de atendimento psicológico dentro do Centro de Acolhida; entretanto, não contempla ações que visem incentivar e fortalecer ao atendimento individual dos refugiados.

Sobre as recomendações do Plano que ainda não estão em prática, podemos citar: a definição de um Hospital Referenciado na Região Central e a alocação de pessoas especializadas - que deverão atuar como pontos focais nas unidades de saúde -, com o objetivo de definir particularidades, principais enfermidades que acometem os refugiados e usar o momento do atendimento para identificar outras demandas e encaminha-los conforme a necessidade.

\subsection{Moradia}

Segundo Plano Estadual (2014, p.11): "O direito à moradia significa mais do que apenas um teto sob o qual viver; ele deve ser visto como o direito de viver de forma segura, em paz e com dignidade.". Logo, para ser considerado uma moradia, o local deve preencher diversos requisitos, tais como: segurança, habitabilidade, acessibilidade, localização e adequação cultural. Conforme afirma Moreira (2012), a obtenção moradia é parte fundamental do processo positivo de integração local.

A realidade hoje enfrentada pelos refugiados e solicitantes não se aproxima em muitos aspectos do cenário ideal de moradia. Diversos são os fatores que dificultam o processo da integração neste âmbito, como explicitado pelo próprio Plano Estadual no parágrafo a seguir (2014, p.11):

Muitos(as) refugiados(as) chegam ao Brasil sem nenhum recurso financeiro e dependem da disponibilidade da comunidade e de espaço em moradias populares no primeiro momento. Outra questão que representa um obstáculo para que os(as) refugiados(as) tenham acesso à moradia é o elevado custo dos aluguéis e a burocracia excessiva para se alugar um imóvel.

Em geral, a situação na qual os refugiados chegam ao Brasil não é favorável para assegurar o aluguel de um imóvel: desempregados e em muitos casos sem documentos e/ou reservas monetárias, muitos buscam auxilio com cidadãos congoleses que já residam no Brasil. Entretanto, devido à condição socioeconômica da maioria dos refugiados, as moradias não têm a infraestrutura necessária para abrigar mais de uma composição familiar. Os entrevistados contam suas experiências com a moradia no Brasil, em especial no período de chegada ao país:

Era difícil quando eu cheguei eu não conseguia moradia, estava morando na casa de um congolês que é pastor e que em acolheu e me ajudou muito, até que eu, quando eu consegui o trabalho, eu com a minha irmã, depois que a gente conseguiu trabalho, a gente saiu. (Migrante 1)
É possível observar que muitos entrantes seguem morando de favor por um longo período, devido às dificuldades em encontrar empregos e do excesso de burocracia e alto valor cobrado para a locação de imóveis. Tal fato acarreta no afastamento dos refugiados e solicitantes para bairros mais distantes e/ou favelas. Devido ao risco de algumas dessas regiões, a população está buscando novos locais para morar. Essa mudança prejudica outros aspectos da integração local, como explica a Coordenadora da Assistência Social:

Antes eles se concentravam muito no município do Rio, alguns anos atrás eles começaram a ir pra outros municípios, Duque de Caxias principalmente [...]. Então principalmente mulheres com crianças pelo medo da violência acabaram se afastando cada vez mais. [...] Quanto mais longe você mora do centro, mais difícil você ter trabalho, porque o empregador sempre leva em consideração essa distância; e também mais precários são os serviços que ele recebe. [...] Então eles acabam tendo um acesso cada vez mais precarizado, um acesso pior a essas políticas de integração (Funcionário 1).

Outro ponto que merece atenção é a garantia de um local para morar nos primeiros dias, quando o solicitante ainda não possui nenhum documento. No Rio de Janeiro, não existem abrigos próprios para a população refugiada, que se vê obrigada a buscar moradia nos abrigos convencionais. Além disso, programas de financiamento de moradias de baixo custo, como o "Minha Casa, Minha Vida", não permitem a participação de refugiados, sendo essa mais uma barreira para a integração local. Todavia, no último relatório publicado pela CONARE (2016, p.27), ao tratar de soluções duráveis, o documento coloca como uma das metas a "Desburocratização do acesso ao Minha Casa, Minha Vida".

Dentre os produtos previstos pelo Plano Estadual, também estão delineadas metas acerca da inclusão de refugiados em políticas de moradia de baixo custo, concessão de crédito e auxílios financeiros. Também, consta no documento, a meta de ampliação dos serviços existentes de acolhida e abrigo para refugiados. Nenhuma dessas ações está em fase de implementação atualmente.

\subsection{Emprego e Renda}

O emprego é um dos principais eixos da integração local - é a partir da renda que o refugiado terá acesso aos outros direitos e necessidades básicas, como moradia, alimentação, vestuário, entre outros. Segundo Plano estadual (2014, p.9):

Os(as) refugiados(as) devem ser capazes de sustentar a si e suas famílias, especialmente quando não existe qualquer perspectiva de retorno ao país de origem. E é por meio do trabalho regular que os(as) refugiados(as) poderão adquirir sua autonomia.

Contudo, ainda que o direito ao emprego esteja previsto em lei, e que a carteira de trabalho seja um dos primeiros documentos fornecidos ao solicitante de refúgio, diversas são as barreiras que a população enfrenta ao procurar um meio de subsistência. Como citado por Franco (2016), o desemprego e pauperismo é parte da cotidiano dos refugiados no Brasil.

Segundo relatos dos funcionários, as principais dificuldades na busca por emprego são o idioma - dado que a língua falada no Congo é o francês, seguido dos dialetos locais do país - e o desconhecimento acerca de sua cultura, principalmente por parte dos empregadores, que não compreendem certos aspectos do 
refúgio, como por exemplo: as razões pelas quais a maioria dos refugiados não possui documentação do seu país de origem, ou apresentam dificuldades em comprovar a veracidade das informações; porque a carteira de validade dos solicitantes possui uma data de validade reduzida; entre outros. Os refugiados entrevistados também destacam o desconhecimento acerca do tema do refúgio pela população geral como uma barreira: a falta de informação gera a sensação de desconfiança nos empregadores.

Um ponto de atenção é que, mesmo quando a inserção no mercado de trabalho ocorre, esta tende a ser fora da área em que o refugiado atuava posteriormente a chegada no Brasil. Uma das principais razões para esse fato é a dificuldade da comprovação de experiência e validação dos diplomas.

Independentemente de ser engenheiro ou se ele tem nível fundamental / nível médio ele vai normalmente se inserir no mercado de trabalho nas mesmas funções, né, porque não tem como comprovar essa qualificação. [...] Muitas vezes eles até se inserem no mercado formal, mas em funções que exigem pouca qualificação, e que tem salários mais baixos também: carga e descarga, limpeza, normalmente eles acabam se inserindo nessas funções. $E$ alguns deles também na área de hotelaria, por conta do idioma (Funcionário 3).

No caso dos congoleses, também existe um preconceito racial, pela cor da pele e também pela concepção que muitas pessoas têm a respeito dos africanos. A maioria dos depoimentos dos funcionários mostram que os empregadores utilizam-se de estereótipos para contratar, ou barrar a contratação de refugiados.

No caso das mulheres, há também a questão dos filhos, já que muitas chegam grávidas e/ou acompanhadas de filhos menores de idade. Essa composição familiar dificulta ao procurar emprego, visto que a maioria das refugiadas não possui parentes com quem deixar as crianças enquanto trabalham.

Tudo pra mim, morar aqui, porque não tem família, é difícil. Pra mim é difícil porque vou pagar a moça que vai ficar com meu filho, vou pagar aluguel, comida, eu ganho mil e pouco, imagina, faz o cálculo. Vou pagar almoço, 400, aluguel 500, luz, comida... e depois? (Migrante 2)

Apesar das dificuldades, os funcionários relataram alguns casos de empregadores que se sensibilizam com a condição dos refugiados, contratam e acabam surpreendendo-se com o desempenho deles.

Os funcionários relataram que a Cáritas possui parcerias com o Ministério do Trabalho, disponibilizando voluntários especializados no atendimento aos refugiados. Além disso, a Cáritas atua intensivamente na sensibilização de empregadores, buscando estabelecer parcerias com empresas, visando gerar mais empregos destinados à população refugiada. O Centro de Acolhida também promove palestras a respeito da importância do currículo, como portar-se em uma entrevista, entre outros.

No que diz respeito ao Plano Estadual, dentre os produtos previstos pelo documento que já foram executados, podemos citar a Cartilha do Trabalhador Refugiado e Solicitante de Refúgio, desenvolvida pela Cáritas em parceria com o Ministério do Trabalho e o ACNUR

Com relação aos produtos que estão sendo colocados em prática gradualmente, podemos perceber: a facilitação do acesso aos programas sociais, como o "Bolsa Família"; promoção de seminários com empresas e instituições de interesses e premiação de parceiros, por meio de reconhecimentos e/ou incentivos fiscais.

Durante as observações de Campo, vimos a cartilha presente na mão de diversas crianças e alguns adultos, após o fim das aulas de português. Apesar disso, notamos, também, que muitas mulheres passam o dia na sede do Centro Acolhida à espera de doações e auxílio financeiro, dos quais dependem devido à dificuldade em recolocar-se no mercado de trabalho. Presenciamos a divisão de cobertores, fraldas descartáveis e roupas para crianças. Algumas mulheres que chegaram mais tarde ao local não conseguiram nenhuma doação e foram orientadas por funcionárias a retornar em outro momento.

. Assim, apesar de autores como Moreira (2012) defenderem que o direito ao trabalho é garantido ao refugiado no Brasil, ainda na condição de solicitante de refúgio, na prática, existem fortes impecílios, que vão além dos entraves burocráticos, conforme será discutido mais a frente, para que o acesso ao emprego e à renda, especialmente no mercado formal e dentro da área de formação do refugiado, seja efetivamente garantido.

\subsection{Educação}

A categoria da educação engloba não somente à garantia de acesso às instituições de ensino para todas as idades, mas, também, a validação e reconhecimento do ensino recebido pelos refugiados em seu país de origem. Conforme visto anteriormente, a validação de diplomas e o acesso à educação estão contemplados como parte do conceito de integração local previsto na Lei $n^{\circ}$ 9.474/97. Conforme o Plano Estadual (2014, p.8):

A lei brasileira de refúgio em seu artigo 44 reconhece o direito dos(as) refugiados(as) de terem acesso à educação e prevê que o reconhecimento de certificados e diplomas necessários para 0 ingresso em instituições acadêmicas de todos os níveis deverão ser facilitados para os(as) refugiados(as), tendo em conta a situação desfavorável dos(as) mesmos(as).

Ao discutir o tema com os entrevistados, percebemos duas realidades distintas: tratando-se das crianças em idade escolar (a partir dos quatro anos), o acesso à educação ocorre sem grandes complicações; após a obtenção do protocolo já é possível realizar a matrícula. $\mathrm{O}$ aprendizado do português entre as crianças também ocorre de maneira mais fácil. Durante a observação de campo, foi notável a fluência delas ao falar o idioma, quando comparadas aos adultos. Durante a análise, vimos crianças usando uniformes das escolas públicas do Rio de Janeiro, o que demonstra que estas, de fato, conseguem o acesso à educação. Além disso, a maioria delas já falava a língua portuguesa fluentemente.

Para as crianças menores de quatro anos, o acesso às creches é mais complexo. Esse não é um problema exclusivo dos refugiados, mas de todas as mulheres no estado que dependem da rede pública. Já existe hoje uma portaria municipal que defende a prioridade para mães refugiadas, porém, ainda é pouco efetiva, devido à falta de vagas que dificulta a inserção no mercado de trabalho.

Já no caso dos adultos, o aceso à educação e reconhecimento de diplomas tem ainda mais barreiras. Segundo os funcionários, os refugiados apresentam diversos níveis de escolaridade, com 
predominância do ensino médio. Porém, em um primeiro momento, o grau de escolaridade não terá relevância, em razão à dificuldade da comprovação e da inserção no mercado de trabalho dentro da área que estudava ou trabalhava previamente.

Quando os refugiados optam por realizar a comprovação ou equivalência de escolaridade no Brasil, existem diferentes processos, com base no grau de escolaridade e nos documentos comprobatórios disponíveis.

Para os ensinos fundamental e médio, o refugiado deverá levar os documentos que comprovem a escolaridade até a Secretaria de Educação, que irá analisar e realizar a equivalência do diploma. Caso a pessoa não possua tais documentos, deverá realizar uma prova de nivelamento, que identificará com base em sua pontuação qual o ano escolar equivalente. O processo é claramente falho, uma vez que a prova é escrita e respondida em português, além de conter matérias específicas do Brasil. Devido ao conteúdo da prova, muitos acabam regredindo nos estudo e são obrigados a refazer alguns anos escolares no Brasil, o que em alguns casos, pode ser desmotivador.

Para o nível superior, a revalidação ocorre raramente, devido ao processo extremamente complexo e heterogêneo: cada universidade define quais serão os critérios de aceitação dos diplomas. Além disso, o processo é pago e caro considerando a faixa salarial da população refugiada e só pode ser realizado após o deferimento do pedido de refúgio e obtenção do RNE. Para a revalidação, é obrigatório que o refugiado apresente os documentos comprobatórios; caso não possua, não poderá revalidar. Outra barreira são os conselhos, como a Ordem dos Advogados do Brasil $(\mathrm{OAB})$ e o Conselho Regional de Medicina (CRM), que devido suas especificidades locais, são mais rigorosos na análise de equivalências.

O Plano Estadual admite a revalidação de diplomas como uma problemática que deve ser discutida diretamente com as universidades, criando parcerias que visem facilitar ao processo. Além disso, o Plano prevê medidas referentes ao acompanhamento do número de refugiados matriculados em instituições de ensino, viabilizar o ensino da língua portuguesa, incentivar a troca entre refugiados e nacionais dentro das instituições e capacitar a população refugiada para ministrar aulas em suas comunidades. Não foi possível perceber durante a pesquisa aplicações práticas do Plano neste âmbito.

O Plano não contempla ações relacionadas à revisão do método de avaliação e nivelamento de refugiados nos estudos. Hoje não existe uma ação específica que leve em consideração as diferenças do ensino no Brasil e no país de origem dos refugiados, que vise permitir à equivalência e retomada dos estudos sem a depreciação do conhecimento previamente adquirido.

\subsection{Cultura}

Como citado por Moreira (2012), o processo de integração local engloba não apenas fatores políticos e econômicos, mas também culturais. De acordo com o Plano Estadual (2014, p.13), "O preconceito e a falta de conhecimento sobre a realidade e os direitos dos(as) refugiados(as) dificultam sua integração local.". O respeito à cultura dos refugiados, bem como sua aceitação nos meios e sua interação com a população nacional, são de fundamental importância para a garantia de seus direitos. A população refugiada é composta por pessoas de diversos países, principalmente Ásia, África e Oriente Médio (CÁRITAS, 2016), de regiões geograficamente distantes e culturalmente distintas em relação ao Brasil, com costumes e tradições não comuns no nosso país.

Durantes as observações, foi possível notar a preservação da cultura entre os congoleses: entre si, todos conversavam em seus dialetos locais; as mulheres carregavam os bebês conforme a tradição africana: nas costas, utilizando panos amarrados; alguns usavam estampas ou roupas características de sua cultura.

Segundo depoimento da Coordenadora da Assistência Social, a Cáritas/RJ "tem muita preocupação com relação a integração cultural, porque a ideia é que haja uma troca, que eles possam enriquecer nossa cultura e também ter o que é importante na nossa agregada à cultura deles". Assim, o Centro realiza diversos tipos de atividades voltadas para o tema: desde visitas aos museus e pontos turísticos; à organização eventos como feiras culturais, desfiles, workshops; até palestras onde os refugiados falam sobre a condição em escolas e universidades.

Apesar de exaltar a cultura original dos imigrantes, a Cáritas também preocupa-se com a adaptação dos refugiados à cultura local. Ainda de acordo com a Coordenadora: "Uma coisa importante na questão cultural é que a gente sempre tem um limite entre até o momento em que a gente respeita a cultura e a partir de onde a gente precisa colocar como funciona aqui". Logo, ainda que seja importante a preservação da cultura de origem, esta não pode ultrapassar os limites legais estabelecidos no país acolhedor. Por isso, reuniões e palestras são feitas para os refugiados, com o objetivo de informá-los sobre leis e costumes locais, conscientizando da necessidade do respeito mútuo entre nacionais e imigrantes.

Um trecho do depoimento de uma refugiada confirma a afirmação acima:

Quando cheguei aqui, eu vi dois meninos - essa coisa do "veado", por exemplo - na minha terra também tem, mas se você faz uma coisa de "veado" é muito fechado, ninguém vai saber, mas aqui é liberado. Mas gente, é normal, é normal. [...] A gente mora aqui no Brasil, então, tudo é normal, tudo é liberado. Mas eu gosto de tudo liberado, liberado é bom, na minha vida eu também gosto assim. (Migrante 2)

Com relação à discriminação, segundo os relatos, os refugiados sofrem discriminação em alguns casos devido à falta de conhecimento por parte da população, como citado anteriormente. No caso dos Congoleses em especial, estes enfrentam também discriminação racial.

Existe a discriminação por ser refugiado, que aí cai um pouco nisso que eu falei que é o desconhecimento, de não saber quem é a pessoa, que documento é aquele, tudo mais... [...] Mas, e a questão do racismo, eles colocam muito isso também, porque a princípio é algo que nem existe mais né, que não tem... mas é um racismo velado, né... (Funcionário 3 )

Apesar dos relatos de preconceito, a maioria dos refugiados e solicitantes entrevistados demonstraram ter boa relação com os brasileiros e gostar deles. 
Dentro dessa temática, o Plano Estadual prevê iniciativas de valorização da cultura dos refugiados - o que hoje já está sendo colocado em prática, através dos eventos culturais promovidos em parceria com a Caritas. Dentre os pontos ainda não executados, vemos: a ampliação do acesso aos órgãos de segurança pública; a conscientização e sensibilização acerca do refúgio e o treinamento para lideranças refugiadas - visando dar poder de voz aos refugiados na luta por suas causas e direitos perante a sociedade.

Além disso, o plano não contempla ações voltadas para o preconceito racial, sofrido especialmente por refugiados negros, adicional ao preconceito atrelado aos estrangeiros e à condição de refugiado.

\section{CONSIDERAÇÕES FINAIS}

Após as análises realizadas, podemos concluir que o Plano Estadual de Políticas de Atenção aos Refugiados tem como principal objetivo formalizar a necessidade de ações relativas às políticas públicas no âmbito da integração local da população refugiada e solicitante de refúgio. Entretanto, a execução e implementação das diretrizes e objetivos só é possível graças à atuação ativa da Cáritas Arquidiocesana nas atividades de acolhida e integração local.

Conforme explicitado por Frey (2009, p. 226), ao pensar no ciclo de das políticas públicas, este é dividido nas seguintes etapas: "Percepção e definição de problemas, 'agenda-setting', "elaboração de programas e decisão, implementação de políticas e, finalmente, a avaliação de políticas e a eventual correção da ação". É possível notar que dado o fato de que o Plano Estadual foi publicado há apenas dois anos, este ainda encontra-se em fase de implementação. Ainda assim, mesmo com o pouco tempo em vigor, já é possível notar as barreiras burocráticas que impedem o bom andamento da implementação do plano. Dentre as ações que já estão em vigor, muitas ocorrem graças ao trabalho da Cáritas, que executa atividades voltadas a integração local e auxílio à população refugiada, de forma independente do plano.

Desse modo, podemos observar, então, que o fluxo da elaboração das políticas públicas no cenário estudado ocorre em um fluxo diferente do previsto na teoria: a execução e implementação não sucede à elaboração das políticas; é através da necessidade de formalizar as atividades executadas pela Cáritas e outros órgãos e reforçar as parcerias entre os agentes atuantes que se desenvolve o plano. Assim, percebemos que o Plano é de fato uma consequência das atividades visando a integração local, que já aconteciam antes da publicação.

Quando questionados a respeito do Plano Estadual de Políticas de Atenção aos Refugiados, os funcionários da Cáritas não conseguiram exemplificar atos concretos realizados graças ao documento. Esse fato pode ser justificado em razão de que muitas das ações previstas no Plano já estavam sendo elaboradas e até executadas pelo Centro de Acolhida anteriormente. De fato, a Cáritas é membro do CEIPAR, comitê responsável pela criação e implementação, o que justifica a presença de atividades e planos anteriores ao documento na publicação.
Além disso, o excesso de burocracia e o descaso do governo em certos aspectos foram bastante comentados nos depoimentos, como uma das principais oportunidades de melhoria no sentido das políticas públicas. Tais depoimentos confirmam a afirmação de Albuquerque et al (2016), a respeito dos fatores que explicam as dificuldades na integração local: um desequilíbrio na estrutura social, justificada pela burocracia estatal, falta de preparo dos funcionários públicos e a falta de informação da população o acesso aos bens e serviços básicos previstos em lei como direitos de todos os cidadãos.

Vale ressaltar, entretanto, que os entraves à integração local não se resumem apenas aos fatores burocráticos apontados por Albuquerque et al. Foi possível constatar nos relatos dos refugiados e de funcionários de Cáritas que tais problemas burocráticos vêm entrelaçados por uma série de questões sociais, como o preconceito racial e cultural sofrido pelos refugiados, ou dificuldades de acesso aos direitos básicos que não se restringem somente a eles, mas que afligem toda a classe trabalhadora brasileira. Nesse sentido, outros aspectos sociais e econômicos complexificam a realidade dos refugiados, para além de questões meramente administrativas.

Através da pesquisa, percebemos que certos aspectos da integração local estão mais desenvolvidos que outros. Temos como exemplos, a documentação, a saúde e a educação pública: em todos os casos, já existem parcerias consolidadas com o poder público, que facilitam a articulação entre as entidades que cuidam dos refugiados e os serviços públicos a serem prestados. Segundo Moreira (2012), o acesso a esses dois serviços públicos é parte fundamental da integração local.

As parcerias permitem uma maior troca de informações, e por consequência, maior compreensão acerca do tema do refúgio e suas particularidades. Essa articulação também reflete na impressão que os refugiados têm acerca dos serviços recebidos. A documentação, por ser responsabilidade do CONARE, em parceria com a Policia Federal, também tem processos mais desenvolvidos e unificados em todo o país. No caso da saúde e da educação, esses são serviços públicos garantidos pelo governo Estadual e Municipal, logo, são menos homogêneos.

Em contrapartida, aspectos como a moradia e o emprego ainda possuem barreiras acentuadas que dificultam a efetivação dos direitos. Em ambos os casos, ainda não existem parcerias sólidas e o nível de burocracia é alto. A dificuldade nessas duas categorias tem o agravante dado que estes são os dois âmbitos no qual o refugiado necessita auxílio desde o primeiro dia em que chega ao Brasil. A integração falha nesses aspectos prejudica diretamente os demais componentes da integração local.

É possível identificar, também, que as categorias que requerem maior envolvimento da população tendem a ser mais problemáticas. No caso da moradia, o Estado não controla diretamente as negociações de locação de imóveis. Para o emprego, também fazse necessário o auxílio das empresas privadas, as quais decidem por contratar ou não a população refugiada.

Outro ponto importante a respeito do Plano é que este falha ao generalizar os refugiados e solicitantes; o documento não leva em 
conta as especificardes de cada população entrante, que são provenientes de diferentes países e com aspectos culturais, características físicas, de saúde distintos; além das diferentes origens e formatos dos conflitos que os forçaram a deixar o local onde viviam.

Vemos o impacto da generalização nos depoimentos dos refugiados congoleses: questões como o preconceito racial, a dificuldade do idioma e os aspectos demográficos - como o número elevado de mulheres e crianças em comparação com a média - não são explicitados no plano e podem em muitos casos acentuar e até produzir dificuldades no processo de integração. A percepção que a população brasileira tem a respeito de africanos, por exemplo, pode agravar situações de integração cultural e obtenção de empregos; as dificuldades em encontrar vagas em creches é um fator de maior percepção pelos congoleses, em razão de que estes possuem um número muito maior de gestantes e crianças abaixo da idade de alfabetização; entre outros. Esses aspectos mostram que questões particulares de cada cultura merecem atenção na formulação e implementação de planos e políticas públicas.

O crescimento acelerado da demanda por refúgio no Brasil possui prós e contras para os refugiados: por um lado, o contingente torna-se insustentável à medida que cresce sem que os serviços prestados passem por um crescimento proporcional, o que gera atrasos nos processos e diminuição da atenção individual dada a cada solicitante e refugiado. Apesar disso, o crescimento estimula a discussão acerca do tema, que passa a ganhar maior visibilidade na mídia, sensibilizando a população acerca da questão do refúgio. O impulso causado através da mídia reflete no desenvolvimento de mais políticas públicas que visem amenizar os problemas.

Vemos também que, ainda que para facilitar a compreensão e obtenção de dados para a presente pesquisa, tenha sido necessário desmembrar a integração local em diferentes categorias, na prática, todas essas classificações estão diretamente conectadas e são interdependentes. Não é possível obter moradia sem emprego, emprego sem educação, etc.

Desse modo, concluímos que apesar dos avanços realizados no âmbito da integração local dos refugiados e solicitantes de refúgio, ainda há um longo caminho a ser percorrido entre a elaboração das políticas públicas e a implementação destas. É preciso diminuir as barreiras burocráticas, bem como assegurar maior presença do poder público na execução das ações previstas por políticas como o Plano Estadual.

Assim, é imprescindível a constante revisão e adaptação das ações e leis que permeiam o tema. Fazem necessários também os ajustes mais específicos nas políticas que levem em consideração não apenas os refugiados e solicitantes como um grupo único, mas também as subdivisões por ele contemplado, a partir de cada cultura e país dos quais a população refugiada é proveniente.

\section{REFERÊNCIAS}

ACNUR. (1997). Lei n. 9.474 de 22 de julho de 1997. In ACNUR; IMDH. Lei 9.474/97.

ACNUR. (2011). Encontro no Rio discute emprego e renda para refugiados no Brasil. Disponível em: <http://www.acnur.org/t3/portugues/noticias/noticia/parceria-no-rio-dejaneiro-cria-emprego-para-refugiados/>. Acesso em: 25 maio 2016.
ACNUR. (2012). Com apoio de ONGs e empresas, refugiados conseguem emprego. Disponível em: http://www.acnur.org/t3/index.php?id=242\&tx_ttnews\%5Btt_news\%5D=1008 9> Acesso em: 25 maio 2016.

ACNUR. (2016) Congoleses representam atualmente a maioria dos refugiados no Rio de Janeiro. Disponível em: $<$ http://www.acnur.org/t3/portugues/noticias/noticia/com-apoio-de-ongs-eempresas-refugiados-conseguem-emprego/>. Acesso em: 21 de junho de 2016

ACNUR. Planejamento de Meios de Subsistência no ACNUR: Guia Operacional. 2012.

ACNUR. O que é a Convenção de 1951? Disponível em: < http://www.acnur.org/portugues/informacao-geral/o-que-e-a-convencao-de1951/>. Acesso em: 25 maio 2016

ACNUR. (2014). Protegendo Refugiados no Brasil e no Mundo. 2014 Disponível em:

$<$ http://www.acnur.org/fileadmin/scripts/doc.php?file=fileadmin/Documentos/p ortugues/Publicacoes/2014/Protegendo_refugiados_no_Brasil_e_no_mundo 2014 >. Acesso em: 19 de junho de 2016.

ACNUR. (2013). Metodologia e Técnicas para Entrevistar Solicitantes de Refúgio: Módulo de Capacitação.

ACNUR. (2015). Mid-Year Trends 2015. Genebra.

Albuquerque, J; Gabriel M.; Anunciação R. F. M. (2016) O Papel Do Entorno No Acolhimento E Na Integração De Populações Migrantes Para O Exercício Pleno Da Cidadania. Refúgio e Hospitalidade. Kairós Edições. Curitiba.

Aydos, Mariana Recena; Baeninger, Rosana; Dominguez, Juliana. (2008). Condições de Vida da População Refugiada no Brasil: trajetórias migratórias e arranjos familiares. III Congresso da Associação Latino-Americana de População. Córdoba.

Baeninger, Rosana. (2008). População Refugiada: retrato das condições de vida das famílias em São Paulo e Rio de Janeiro. Campinas.

Bacelar, Carina. (2015). Refugiadas sofrem mais para obter trabalho. Folha de São Paulo, Rio de Janeiro.

BRASIL.(2004). Constituição da República Federativa do Brasil. 1988. São Paulo: Atlas.

BRASIL. Lei № 5.889, De 8 De Junho De 1973. Disponível em < http://www.planalto.gov.br/ccivil_03/leis/L5889.htm >. Acesso em 02 de Julho de 2016.

BRASIL. Programa Nacional de Direitos Humanos III. 2009. Disponível em: <http://www.planalto.gov.br>. Acesso em: 26 maio 2016.

BRASIL. Ministério do Trabalho e Emprego. Memorando de Entendimento. 2013. Disponível em: <http://www.lex.com.br/legis 24997503 MEMORANDO DE ENTENDIMEN TO.aspx >. Acesso em: 27 maio 2016.

CÁRITAS-RJ. (2016). Cartilha do Trabalhador Refugiado e Solicitante de Refúgio. Rio de Janeiro.

CÁRITAS-RJ. Centro de Acolhida aos Refugiados. Disponível em: < http://caritas.org.br/projetos/programas-caritas/refugiados>. Acesso em: 30 maio 2016.

CÁRITAS-RJ. O que Fazemos. Disponível em < http://www.caritas-rj.org.br/oque-fazemos.html >. Acesso em: 30 maio 2016.

CÁRITAS-RJ. (2016). Números do Refúgio no Rio de Janeiro. Rio de Janeiro CEIPAR. (2014). Plano Estadual de Políticas de Atenção aos(às) Refugiados(as). Rio de Janeiro.

CONARE. Sistema de Refúgio brasileiro: Desafios e Perspectivas. 2016. Disponível em: $<$ http://www.acnur.org/t3/fileadmin/scripts/doc.php?file=t3/fileadmin/Docume ntos/portugues/Estatisticas/Sistema de Refugio brasileiro -

_Refugio_em_numeros_-_05_05_2016>. Acesso em: 30 mäio 2016.

CONARE. Coletânea de Instrumentos de Proteção Internacional dos Refugiados.

ESTADO DO RIO DE JANEIRO. Decreto n. 42.182 de 11 de dezembro de 2009. Disponível em: <http://www.jusbrasil.com.br/diarios/32132782/doerjpoder-executivo-09-11-2011-pg-19>. Acesso em: 12 dez. 2009.

Franco, Samara V. (2016). MIGRAÇÕES FORÇADAS: Um estudo acerca do refúgio na atualidade. $R$. Direitos, trabalho e política social, Cuiabá. v2, n2, p. 69-85.

Frey, Klaus. (1999). Análise De Políticas Públicas: Algumas Reflexões Conceituais E Suas Implicações Para A Situação Brasileira. PPGSPI/UFSC, Cadernos de Pesquisa, $n^{\circ} 18$. Florianópolis.

IBGE. (2014). Produto interno bruto dos municípios: 2012. Instituto Brasileiro de Pesquisas e Estatísticas - IBGE. Rio de Janeiro.

Jubilut, Liliana Lyra. O Procedimento de Concessão de Refúgio no Brasil. ed. Ministério da Justiça. 18p. Disponível em: <http://portal.mj.gov.br/main.asp?Team=\%7BC728A416-5AA7-476D-B239CC89FFB36301\%7D> agosto 2014. Acesso em: 30 de maio de 2016

Jubilut, Liliana Lyra. (2010). Enhancing refugees' integration: new initiatives in Brazil. Forced Migration Review, v. 35. p. 46-47.

Maciel, Edgar. (2016). Chegada de refugiados faz xenofobia crescer mais de $600 \%$ no Brasil, mas nem $1 \%$ dos casos chega à Justiça. Huffpost Brasil. Junho de 2016 Disponível em: 
http://www.brasilpost.com.br/2016/06/20/xenofobia-brasiljustica_n_10558742.html >. Acesso em 17 de junho de 2016.

Minayo, Maria Cecília de Souza (org.). (2010). Pesquisa social: teoria, método e criatividade. 29. ed. Petropolis, RJ: Vozes.

Moreira, Julia Bertino; Baeninger, Rosana. (2010). Local integration of refugees in Brazil. Forced Migration Review, v. 35, p. 48-49.

Moreira, Julia Bertino. (2010). Redemocratização e direitos humanos: a política para refugiados no Brasil. Rev. Bras. Polít. Int., v. 53, p. 111-129.

Moreira, Julia Bertino. Política (2012). Em Relação Aos Refugiados No Brasil (1947-2010). Tese (doutorado) - Universidade Estadual de Campinas, Instituto de Filosofia e Ciências Humanas. Campinas.

ONU. (2016). Arquidiocese do Rio e Cáritas celebram 40 anos de trabalho com refugiados e apresentam raio-X do refúgio no $\mathrm{RJ}$. Disponível em: < https://nacoesunidas.org/arquidiocese-do-rio-e-caritas-celebram-40-anosde-trabalho-com-refugiados-e-apresentam-raio-x-do-refugio-no-rj/>. Acesso em: 01 junho de 2016.

ONU. (2016). Mais de 6 mil refugiados e solicitantes de Angola, RD Congo e outros países vivem no RJ. Disponível em: < ttps://nacoesunidas.org/maisde-6-mil-refugiados-e-solicitantes-de-angola-rd-congo-e-outros-paisesvivem-no-rj/>. Acesso em: 27 maio 2016

ONU. (2016). Refugiados contam histórias de preconceito e hospitalidade em sua vida no Brasil. Disponível em: < https://nacoesunidas.org/refugiados- contam-historias-de-preconceito-e-hospitalidade-em-sua-vida-no-brasil//>. Acesso em: 23 de junho de 2016

Pamplona, Danielle A.; Piovesan, Flávia. (2015). Instituto Do Refúgio No Brasil: Práticas Recentes. Revista de Direitos Fundamentais e Democracia. Curitiba.

Peterman, Amber; Palermo, Tia; Bredenkamp, Caryn. (2011). Estimates and determinants of sexual violence against women in the Democratic Republic of Congo. American Journal of Public Health, v. 101, n. 6, p. 1060-1067.

Ribeiro Jr., Valdir. (2016). Comitê Intersetorial para Refugiados retoma atividades no Rio de Janeiro. 2016. Disponível em: <http://revistapegn.globo.com/Mulheres-

empreendedoras/noticia/2016/03/projeto-da-onu-no-brasil-ajuda-refugiadasentrarem-no-mercado-de-trabalho.html>. Acesso em: 18 de junho de 2016.

Secchi, Leonardo. (2010). Políticas públicas: conceitos, esquemas de análise, casos práticos. Cengage Learning, v. 133. São Paulo.

Souza, Fabricio T. (2014). O êxodo dos refugiados e o direito a resistir. Revista Direito e Práxis, vol. 5, n. 9, 2014, pp. 101---117. Rio de Janeiro.

Valenzola, Renato H. (2013). O Conflito Na República Democrática Do Congo E A Ausência Do Estado Na Regulação Das Relações Sociais. Revista LEVS/UNESP-Marília - Edição 12 Novembro/2013. Marília.

Vergara, S. (2014). Projetos e Relatórios de Pesquisa em Administração. 15. ed. São Paulo: Atlas. 